\title{
Dynamic hyperinflation and flow limitation during methacholine- induced bronchoconstriction in asthma
}

\author{
C. Tantucci*, M. Ellaffi ${ }^{+}$, A. Duguet ${ }^{+}$, M. Zelter ${ }^{+}$, T. Similowski ${ }^{+}$, J-P. Derenne ${ }^{+}$, J. Milic-Emili $^{+}$
}

Dynamic hyperinflation and flow limitation during methacholine-induced bronchoconstriction in asthma. C. Tantucci, M. Ellaffi, A. Duguet, M. Zelter, T. Similowski, J-P. Derenne, J. Milic-Emili. (C) ERS Journals Ltd 1999.

ABSTRACT: Although persistent activation of the inspiratory muscles and narrowing of the glottic aperture during expiration have been indicated as relevant mechanisms leading to dynamic hyperinflation in acute asthma, expiratory flow limitation (EFL) has recently been proposed as a possible triggering factor for increasing endexpiratory lung volume (EELV).

To establish whether the attainment of maximal flow rate during tidal expiration could elicit dynamic elevation of EELV, breathing pattern, change in EELV by measuring inspiratory capacity (IC) and occurrence of EFL by the negative expiratory pressure (NEP) method were monitored in 10 stable asthmatic subjects during methacholine-induced, progressive bronchoconstriction in seated position. Change in dyspnoea was scored using the Borg scale.

At maximum response forced expiratory volume in one second (FEV1) fell on average by $45 \pm 2 \%$ ( $<<0.001$ versus control), while IC decreased $29 \pm 2 \%$, (by $0.89 \pm 0.07$ $\mathrm{L},(\mathbf{p}<0.01$ versus control)). Only 2 subjects exhibited EFL at the end of methacholine challenge. In 7 subjects EELV started to increase before the occurrence of EFL. Dyspnoea, which increased from $0.2 \pm 0.1$ to $5.5 \pm 1.0$ (Borg scale) at maximum response $(\mathbf{p}<0.001)$, was significantly related to the level of bronchoconstriction as assessed by change in $(\Delta) F E V 1(r=0.72 ; p<0.001)$ and to dynamic hyperinflation as measured by $\triangle I C(r=0.50 ; p<0.001)$. However, for both $\triangle F E V 1$ and $\triangle I C$ the slope of the relationship with increasing dyspnoea was highly variable among the subjects.

It is concluded that in acute methacholine-induced bronchoconstriction, dynamic hyperinflation may occur in the absence of expiratory flow limitation and that expiratory flow limitation does not represent the triggering factor to generate dynamic hyperinflation. In these circumstances, dyspnoea appears to be related to the increase in end-expiratory lung volume and not to the onset of expiratory flow limitation. Eur Respir J 1999; 14: 295-301.
* Clinica di Semeiotica Medica, University of Ancona, Ancona, Italy. ${ }^{+}$Laboratoire de Physiopathologie Respiratoire du Service de Pneumologie et Service d'Exploration Fonctionelle Respiratoire, Groupe Hospitalier Pitié-Salpetrière, University of Paris VI, Paris, France. "Meakins-Christie Laboratories, McGill University, Montreal, Québec, Canada.

Correspondence: C. Tantucci, Clinica di Semeiotica Medica, Ospedale Regionale Torrette, 60020 Ancona, Italy. Fax: 39 071883913

\section{Keywords: Asthma}

dynamic hyperinflation

dyspnoea

flow limitation

negative expiratory pressure

Received: November 301998

Accepted after revision March 151999

Supported by a grant from Ministero dell' Università e della Ricerca Scientifica e Tecnologica of Italy and by UPRES 2397 (M. Zelter, J-P. Derenne, T. Similowski).

This work has been presented as an oral communication at the ERS Annual Congress, Berlin, Germany, September 20-24, 1997.
Acute bronchoconstriction in asthma is commonly associated with dynamic pulmonary hyperinflation which is reflected by a progressive elevation in end-expiratory lung volume (EELV) above the relaxation volume $\left(V_{\mathrm{r}}\right)$ of the respiratory system [1]. In part, this can be attributed to the increased expiratory airway resistance which would decrease expiratory flow such that $V_{\mathrm{r}}$ cannot be reached within the available expiratory time $(t \mathrm{E})$, which is often reduced during asthma attacks [2]. Indeed, a prolonged time constant of the respiratory system and decreased expiratory time represent mechanisms which may cause dynamic hyperinflation. On the other hand, several studies have shown that in asthma during spontaneous or induced acute bronchoconstriction there is persistent tonic contraction of inspiratory muscles during expiration [3, 4] and glottic constriction [5] which may play a major role in dynamically raising EELV [6]. Recently, during acute methacholine (MCh)-induced bronchoconstriction in asth$\mathrm{ma}$, the occurrence of expiratory flow limitation (EFL) has been proposed as an alternative cause of dynamic hyperinflation through a premature reflex activation of the inspiratory muscles and a consequent transient decrement of the expiratory time [7].

The purpose of this study was to establish whether dynamic hyperinflation is associated with EFL during MCh-induced bronchoconstriction in asthmatics and if this is a key factor that regulates EELV under these conditions. The negative expiratory pressure (NEP) method was used to assess EFL [8].

\section{Methods}

Subjects

Ten asymptomatic mild asthmatic subjects (6 females) were studied whilst in a clinically stable condition. No antiasthma drugs were taken by the subjects at the time of the study. A standard bronchial challenge test with MCh had been previously performed in all subjects to assess airway responsiveness. MCh challenge results were expressed as the cumulative dose of MCh inducing a $20 \%$ fall 
in forced expiratory volume in one second (FEV1) (PD20) from the postsaline value (PD20FEV1) [9]. The latter was calculated by linear interpolation of the semi- $\log 10$ doseresponse curve [9]. The study was approved by the local ethics committee and all subjects gave informed consent.

\section{Study design}

Following baseline spirometry and plethysmographic measurements, subjects underwent a MCh bronchoprovocation test according to a dose-response procedure. After saline, at all steps of MCh-challenge (starting $1.5 \mathrm{~min}$ after each MCh dose inhaled) and during recovery from bronchoconstriction obtained by administration of salbutamol, the following measurements were made in this order: 1) degree of breathlessness by using the Borg scale [10]; 2) breathing pattern parameters from the flow and volume signals; 3) development of EFL by the NEP method; 4) change in functional residual capacity (FRC) by measuring inspiratory capacity (IC); and 5) airway obstruction by forced expiratory manoeuvre parameters.

All measurements were performed with the subjects in a sitting position, wearing a nose-clip. During the study, the neck of the subjects was held in a fixed neutral position to avoid changes associated with neck extension [11].

\section{Methacholine challenge testing}

Progressive airway obstruction was obtained by stepwise doubling of the MCh cumulative dose, until one of the predefined termination criteria was reached. Both saline and MCh were administered by a dosimeter (Mediprom FDC 8; Mediprom, Paris, France). The values obtained postsaline were labelled as control values. The test was stopped when FEV1 decreased by $>50 \%$ of the postsaline value, or when a plateau in FEV1 was reached $(<5 \%$ change in FEV1 over three consecutive doses), or when a cumulative MCh dose of $3200 \mu \mathrm{g}$ had been inhaled, or because of excessive discomfort of the subject. The duration of each step was 3 min so that the maximum cumulative dose of $3200 \mu \mathrm{g}$ of MCh could be administered in $<30 \mathrm{~min}$. To reverse bronchoconstriction, salbutamol (200 $\mathrm{mg}$ ) was administered by metered-dose inhaler every 15 min until FEV1 returned to within $10 \%$ of the postsaline value.

\section{Measurements}

A body plethysmograph (Autobox 2800; Sensor Medics, Yorba Linda, CA, USA) was used with a standardized panting frequency of $<1 \mathrm{~Hz}$ to measure baseline thoracic gas volume at end-expiration (FRC). Maximal flow-volume curves, to obtain forced vital capacity (FVC), FEV1, and mean maximal expiratory flows between $25-75 \%$ of FVC measured at isovolume (forced mid-expiratory flow FEF25-75\%) were performed by a Medical Graphics 1700 system (Medical Graphics, St. Paul, MN, USA) according to recommended techniques [12], without an end-inspiratory pause, both at baseline and at each step of the MCh-challenge testing. (IC) was also measured from the flow-volume curve. Total lung capacity (TLC) was calculated as the sum of FRC and baseline IC. Change in
EELV was monitored during the bronchoprovocation test by computing the difference between TLC and IC, assuming that TLC did not change with MCh-induced bronchoconstriction [13]. The predicted values for lung volumes and spirometry were those of the European Coal and Steel Community [14].

The breathing pattern was measured while subjects breathed through a mouthpiece for a 60 -s period. Flow $\left(V^{\prime}\right)$ was measured with a Hans-Rudolph (4700A pneumotachograph, Hans-Rudolph, Kansas City, MO, USA) and a $\mathrm{MP} 45, \pm 2 \mathrm{cmH}_{2} \mathrm{O}$ Validyne differential pressure transducer (Validyne Corp., Northridge, CA, USA) from which tidal volume $(V \mathrm{~T})$ was integrated. Respiratory frequency $(f \mathrm{R})$, inspiratory time $(t \mathrm{I})$, expiratory time $(t \mathrm{E})$, inspirator$\mathrm{y}+$ expiratory time (ttot), inspiratory and expiratory duty cycle $\left(t \mathrm{t} / t_{\text {tot }}\right.$ and $\left.t \mathrm{E} / t_{\text {tot }}\right)$, mean inspiratory and expiratory flow rates $(V \mathrm{~T} / t \mathrm{I}$ and $V \mathrm{~T} / t \mathrm{E})$ and minute ventilation $\left(V^{\prime} \mathrm{E}\right)$ were obtained from volume and flow signals.

The experimental set-up used to assess EFL by the NEP method was similar to that described previously [15]. The dead space of the equipment assembly was $<30 \mathrm{~mL}$ and its pressure-flow relationship was characterized by the following equation $P=0.85 V^{\prime}+0.70 V^{2}$ where pressure $(P)$ is in $\mathrm{cmH}_{2} \mathrm{O}$ and $V^{\prime}$ is in $\mathrm{L} \cdot \mathrm{s}^{-1}$.

During the NEP trials, $V^{\prime}$ was measured with a HansRudolph 4700A pneumotachograph Hans-Rudolph and a MP45, $\pm 2 \mathrm{cmH}_{2} \mathrm{O}$ Validyne (Validyne Corp.) differential pressure transducer. $\mathrm{P}$ was measured at the mouth via a noncompliant polyethylene tube (I.D. $=1.7 \mathrm{~mm}$ ) connected to a differential pressure transducer (DP15, $\pm 150 \mathrm{cmH}_{2} \mathrm{O}$ Validyne; Validyne Corp.). The pressure, flow and volume signals were amplified, low-pass filtered $(50 \mathrm{~Hz})$ and digitized at $100 \mathrm{~Hz}$ by a 16-bit analog-to-digital converter (Direc Physiology Recording System; Raytech Instruments, Vancouver, Canada). The digitized data were stored on the computer hard disk for subsequent analysis. Data analysis was performed using Direc software (version 3.1; Raytech Instruments) and ANADAT software (version 5.1; RTH InfoDat Inc., Montreal, Canada).

In all instances, immediately after recording the breathing pattern and before any forced expiratory manoeuvres, two acceptable NEP tests were made at intervals of $\sim 6$ regular breaths. The NEP $\left(-5 \mathrm{cmH}_{2} \mathrm{O}\right)$ was applied $0.2 \mathrm{~s}$ after the onset of expiration and was maintained throughout the ensuing expiration. Great care was taken to avoid leakage of air around the lips during the application of the NEP, by proper positioning of the mouthpiece and by asking the subjects to hold their lips tight. The application of NEP was not associated with unpleasant sensations or cough.

In general, in comparison with the flow of the previous control tidal expiration, during NEP the expiratory flow either increased, reflecting absence of EFL or did not change throughout the expiration, reflecting the presence of complete or partial intrathoracic EFL (fig. 1). On rare occasions, however, mostly at the start of the MCh challenge test, the application of the NEP resulted in a transient decrease of expiratory flow below control, as a consequence of upper airway collapse or narrowing. In this case, only if the detection of EFL was impeded, the test was discarded and another NEP test performed.

Heart rate and oxygen saturation were recorded continuously by a pulse oximeter (Nellcor N-100; Nellcor Puritan Bennett, Pleasanton, CA, USA). 

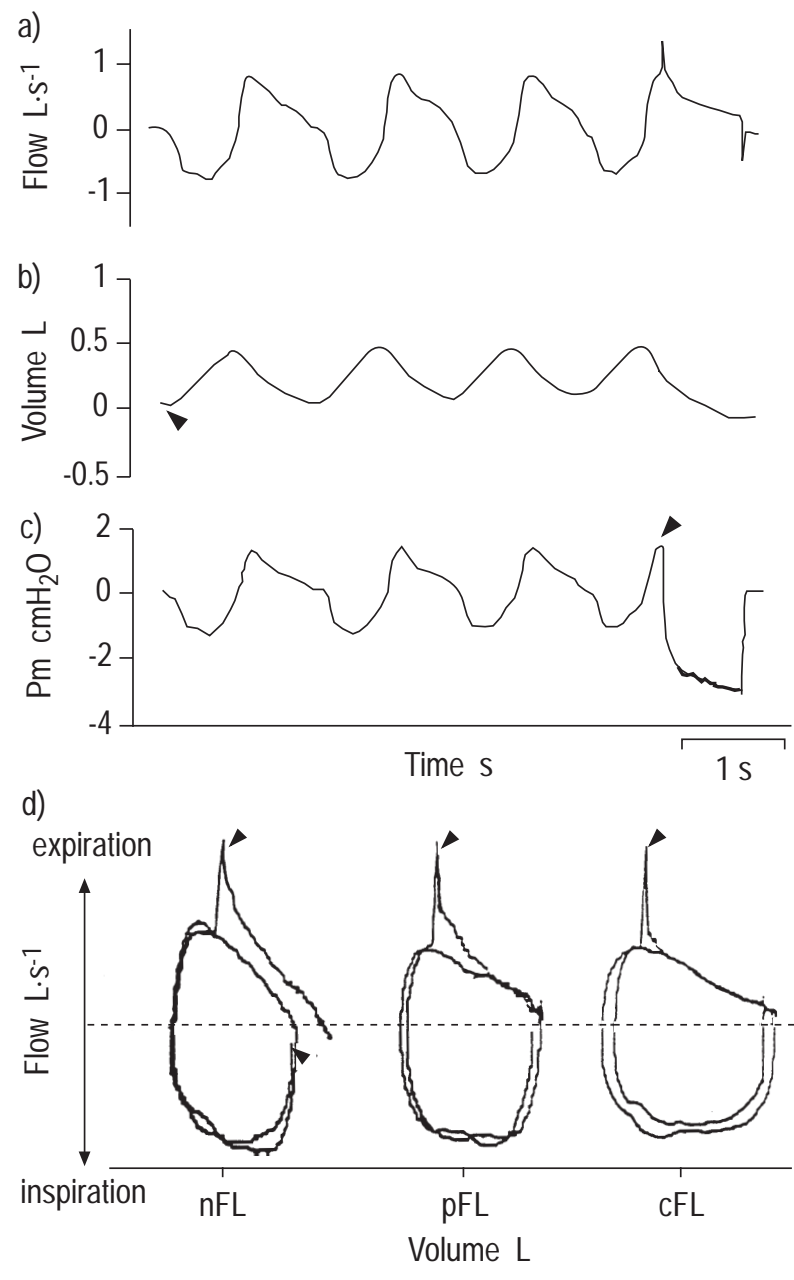

Fig. 1. - The negative expiratory pressure (NEP) method for assessing expiratory flow limitation (EFL). Tracings of a) flow, b) volume and c) mouth pressure $(\mathrm{Pm})$ versus time are depicted during four control resting breaths and application of NEP. Expiration and inspiration in a) was between $1 \mathrm{~L} \cdot \mathrm{s}^{-1}$ and $-1 \mathrm{~L} \cdot \mathrm{s}^{-1}$. Arrowhead in $\mathrm{b}$ ) indicates functional residual capacity (FRC) and in c) it indicates NEP. d) examples of three control tidal flow/volume loops and the corresponding NEP test breaths are shown. In the first example (at left) application of NEP (arrowhead) elicits an increase in flow over the entire control expiration, indicating the absence of expiratory flow limitation (EFL) i.e. no flow limitation (nFL); in the second (in the middle) and third (at right) examples, flow during NEP (application shown by arrowheads) impinges in part or entirely on the flow of the control expiration revealing a partial flow limitation (pFL) or a complete flow limitation (cFL). Arrow indicates FRC.

\section{Dyspnoea evaluation}

Dyspnoea was defined as "an unpleasant sensation of laboured or difficult breathing". The intensity of dyspnoea was assessed with the modified Borg scale [10] to which the subjects were familiarized prior to the study. The endpoints of the Borg scale [10] were 0 representing "no breathlessness" and 10 representing "the most severe breathlessness that they had ever experienced or could imagine experiencing", respectively.

\section{Statistical analysis}

Statistical comparison from control to maximum response were performed using Student's paired t-test with the appropriate Bonferroni correction for the lung function measurements and the Wilcoxon matched paired signed ranks test for the Borg score. Contributors to dyspnoea induced by $\mathrm{MCh}$ challenge were determined by Pearson's correlation coefficient with the changes in Borg scale from control to maximum response as the dependent variable and the changes in spirometric parameters and lung volumes as independent variables. Data are expressed as mean \pm SEM. Levels of $\mathrm{p}<0.05$ were considered as significant.

\section{Results}

The anthropometric and baseline function data of the subjects are shown in table 1 . All subjects had normal baseline spirometry (FEV1 $>80 \%$ predicted) and mild airway hyperresponsiveness (PD20FEV1 ranging 91-780 $\mathrm{mg}$ ) at the time of the study.

Four subjects had $\triangle \mathrm{FEV} 1 \geq 50 \%$ compared with control during the MCh-challenge that was stopped according to the protocol; 1 subject attained a plateau in $\triangle \mathrm{FEV} 1$ at $1600 \mu \mathrm{g}$ of cumulative dose of $\mathrm{MCh}(\Delta \mathrm{FEV} 1=37 \pm 1 \%)$; in the remaining 5 subjects the $\mathrm{MCh}$-challenge ended at the final cumulative MCh dose of $3200 \mu \mathrm{g}$. At the first dose of MCh after a $20 \%$ fall in FEV1, no subject exhibited EFL while the decrease in IC was $416 \pm 2 \mathrm{~mL}$, corresponding to a $\triangle \mathrm{IC}$ of $14 \pm 2 \%$. Average responses to $\mathrm{MCh}$ are summarized in tables 2 and 3 . FEV1 fell $45 \pm 2 \%$ from postsaline to the maximum decrease, while the decrease FEF25-75\% amounted to $94 \pm 2 \%$ at isovolume. The mean increase in EELV was $0.9 \pm 0.1 \mathrm{~L}$, corresponding to $30 \pm 5 \%(\mathrm{p}<0.01)$, from postsaline to maximum dose (table 2).

The breathing pattern did not show any significant changes, though a trend towards a faster respiratory rate due to shortening of both $t \mathrm{I}$ and $t \mathrm{E}$ with corresponding increases in mean inspiratory and expiratory flow was observed from postsaline to maximal response. However, at the dose just before a $10 \%$ decrease in IC the breathing pattern was essentially the same as at the dose just after the $10 \%$ decrease in IC, which was considered to reflect the presence of dynamic pulmonary hyperinflation (table 3 ).

According to the NEP technique none of the subjects exhibited EFL either at the MCh dose preceding or corresponding to the initial decrease of IC $>10 \%$ relative to the control value. Eight out of 10 subjects were nonflowlimited (nFL) even at the maximal dose, as shown for a representative subject (No. 10) in figure 2a. At maximal MCh dose in these 8 nFL subjects the increase in EELV amounted to $0.85 \pm 0.06 \mathrm{~L}$ and the reduction in FEV1 and FEF $25-75 \%$ at isovolume was $46 \pm 2 \%$ and $94 \pm 3 \%$, respectively. In two subjects (No. 1 and No. 3) who became flow-limited at the maximal $\mathrm{MCh}$ dose, as depicted in figure $2 \mathrm{~b}$ for subject No. 1, the EELV increased by 0.9 and $1.2 \mathrm{~L}$ while FEV1 and FEF25-75\% at isovolume decreased by 46 and $38 \%$ and by 99 and $90 \%$, respectively.

Moreover the NEP method showed that for most of the subjects who already exhibited a substantial increase in EELV there would have been enough expiratory flow reserve to breathe at the control EELV without flow limitation despite that level of airway obstruction. This fact is illustrated in figure 3 for a representative subject (No. 9 ), and was clearly evident in 7 subjects.

The Borg score of breathlessness increased from "very, very slight" $(0.2 \pm 0.1)$ to "severe" $(5.5 \pm 1.0)$ at maximal 
Table 1. - Anthropometric characteristics and baseline lung function data of subjects

\begin{tabular}{lccccccccccc}
\hline $\begin{array}{l}\text { Subj. } \\
\text { No. }\end{array}$ & $\begin{array}{c}\text { Sex } \\
\text { M/F }\end{array}$ & $\begin{array}{c}\text { Age } \\
\text { yrs }\end{array}$ & $\begin{array}{c}\text { Height } \\
\text { cm }\end{array}$ & $\begin{array}{c}\text { FVC } \\
\% \text { pred }\end{array}$ & $\begin{array}{c}\text { FEV1 } \\
\% \text { pred }\end{array}$ & $\begin{array}{c}\text { FVC/FEV1 } \\
\%\end{array}$ & $\begin{array}{c}\text { FEF25-75\% } \\
\% \text { pred }\end{array}$ & $\begin{array}{c}\text { TLC } \\
\% \text { pred }\end{array}$ & $\begin{array}{c}\text { FRC } \\
\% \text { pred }\end{array}$ & $\begin{array}{c}\text { RV } \\
\% \text { pred }\end{array}$ & $\begin{array}{c}\text { PD20FEV1 } \\
\mu g\end{array}$ \\
\hline 1 & M & 45 & 180 & 109 & 98 & 67 & 55 & 101 & 110 & 85 & 379 \\
2 & $\mathrm{~F}$ & 36 & 172 & 92 & 93 & 79 & 83 & 101 & 85 & 83 & 200 \\
3 & $\mathrm{M}$ & 51 & 160 & 131 & 118 & 70 & 70 & 107 & 90 & 80 & 367 \\
4 & $\mathrm{M}$ & 29 & 171 & 122 & 120 & 83 & 106 & 113 & 100 & 91 & 602 \\
5 & $\mathrm{~F}$ & 31 & 161 & 114 & 125 & 95 & 130 & 107 & 109 & 116 & 570 \\
6 & $\mathrm{~F}$ & 36 & 163 & 94 & 96 & 73 & 78 & 112 & 136 & 104 & 328 \\
7 & $\mathrm{~F}$ & 27 & 170 & 124 & 110 & 78 & 84 & 116 & 100 & 81 & 780 \\
8 & $\mathrm{~F}$ & 33 & 156 & 136 & 127 & 81 & 84 & 110 & 101 & 93 & 94 \\
9 & $\mathrm{M}$ & 26 & 182 & 109 & 99 & 76 & 74 & 105 & 122 & 98 & 436 \\
10 & $\mathrm{~F}$ & 31 & 168 & 103 & 84 & 71 & 48 & 101 & 88 & 91 & 91 \\
Mean \pm SEM & & $35 \pm 3$ & $168 \pm 3$ & $113 \pm 5$ & $107 \pm 5$ & $77 \pm 3$ & $81 \pm 7$ & $107 \pm 2$ & $104 \pm 5$ & $92 \pm 4$ & $316^{*}(91-780)$ \\
\hline
\end{tabular}

Subj. No.: subject number; M: male; F: female; FVC: forced vital capacity; \% pred: percentage of predicted value; FEV1: forced expiratory volume in one second; FEF25-75\%: forced mid-expiratory flow; TLC: total lung capacity; FRC: functional residual capacity; RV: residual volume; PD20FEV1: linear interpolation of the semi-log10 dose-response curve. *: geometric mean \pm range.

bronchoconstriction $(\mathrm{p}<0.001)$. Mean ratings of dyspnoea became significantly higher than control at the dose corresponding to a decrease in $\mathrm{IC}>10 \%(2.9 \pm 1.0 ; \mathrm{p}<0.01)$ (table 2).

Changes from control were analyzed using all data points collected during progressive bronchoconstriction. The variation in Borg score $(\Delta \mathrm{Borg})$ and percentage fall in FEV1 $(\triangle \mathrm{FEV} 1)$ were significantly related: $\Delta$ Borg $=0.27+$ $0.10 \Delta \mathrm{FEV} 1(\mathrm{n}=89, \mathrm{r}=0.72 ; \mathrm{p}<0.001)$. $\Delta$ Borg also correlated with percentage fall in IC $(\Delta \mathrm{IC}): \Delta \mathrm{Borg}=0.87+0.10$ $\Delta \mathrm{IC}(\mathrm{n}=89 ; \mathrm{r}=0.50 ; \mathrm{p}<0.001)$, which in turn was strongly correlated with percentage fall in $\mathrm{FEV} 1: \Delta \mathrm{IC}=0.16+0.64$ $\triangle \mathrm{FEV} 1(\mathrm{n}=89, \mathrm{r}=0.90 ; \mathrm{p}<0.001)$. In addition, $\Delta$ Borg was correlated with the increase in EELV expressed as per cent of TLC $(\Delta \mathrm{EELV} / \mathrm{TLC} \%)$ : $\Delta \mathrm{Borg}=1.0+0.17 \Delta \mathrm{EELV} / \mathrm{TLC} \%$ $(r=0.45 ; p<0.001)$. The degree of breathlessness, however, exhibited a marked intersubject variability for a given level of either $\triangle \mathrm{FEV} 1$ or $\triangle \mathrm{EELV}$. The mean slope of the relationship between $\Delta \mathrm{Borg}$ and $\Delta \mathrm{FEV} 1$ was $0.12 \pm 0.02$ (coefficient of variation $(\mathrm{CV})=61 \%$ ) and between $\Delta \mathrm{Borg}$ and $\Delta \mathrm{IC}$ was $0.18 \pm 0.03(\mathrm{CV})=60 \%)$. Therefore, at maximal response no correlation was found between $\Delta \mathrm{Borg}$ and $\triangle \mathrm{FEV} 1$ or $\triangle \mathrm{IC}$.

\section{Discussion}

The main findings of this study are that during MChinduced bronchoconstriction in asthmatic subjects dynamic hyperinflation may occur without EFL and it is not trig- gered by the development of EFL. In addition, dyspnoea is significantly related to dynamic hyperinflation and is not elicited by the onset of EFL.

The mechanisms leading to dynamic pulmonary hyperinflation in acute asthma have been previously described [2-6]. Although the increase in expiratory resistance is thought to be a major determinant of hyperinflation, recordings of electromyographic activity of the respiratory muscles and earlier studies of lung and chest wall mechanics during acutely induced bronchoconstriction in asthmatics have documented a persistent activation of inspiratory muscles through expiration which, acting as a brake, tends to slow the tidal expiratory flow and may substantially contribute to increases in EELV [2-4,6]. The expiratory narrowing of the glottis, visualized by fibreoptic bronchoscopy, under the same conditions, is an additional mechanism involved in the dynamic regulation of EELV [5]. During induced bronchoconstriction, a spontaneous increase in EELV has been shown to reduce the total positive respiratory muscle work compared to that performed while breathing under the same conditions at control FRC [16]. Thus, dynamic hyperinflation may be seen as a strategy for minimizing the work of breathing and related energy expenditure during acute airway obstruction. However, the factors inducing such an activation of inspiratory muscles during expiration are still unknown. Recently, EFL has been proposed as a possible triggering factor for generating dynamic hyperinflation during acutely induced bronchoconstriction [7]. In other words, in the face of a progressively increasing airway

Table 2. - Lung function and dyspnoea score during methacholine-induced bronchoconstriction

\begin{tabular}{|c|c|c|c|c|c|}
\hline & & Control & IC $>90 \%$ control $^{+}$ & IC $<90 \%$ control $^{\#}$ & Maximal dose \\
\hline FEV1 & $\begin{array}{l}\mathrm{L} \\
\% \text { control }\end{array}$ & $3.56 \pm 0.23$ & $\begin{array}{l}3.16 \pm 0.14 * \\
90 \pm 2\end{array}$ & $\begin{array}{c}2.81 \pm 0.13^{* *} \\
80 \pm 2\end{array}$ & $\begin{array}{c}1.96 \pm 0.16^{* *} \\
55 \pm 2\end{array}$ \\
\hline FEF25-75\% & $\begin{array}{l}\mathrm{L} \cdot \mathrm{s}^{-1 \%} \\
\% \text { control }\end{array}$ & $3.19 \pm 0.37$ & $\begin{array}{l}2.06 \pm 0.28^{* *} \\
66 \pm 7\end{array}$ & $\begin{array}{c}1.41 \pm 0.20 * * \\
46 \pm 5\end{array}$ & $\begin{array}{c}0.24 \pm 0.11 * * \\
6 \pm 2\end{array}$ \\
\hline IC & $\begin{array}{l}\mathrm{L} \\
\% \text { control }\end{array}$ & $3.11 \pm 0.22$ & $\begin{array}{c}2.99 \pm 0.19 \\
97 \pm 1\end{array}$ & $\begin{array}{c}2.64 \pm 0.17 \\
85 \pm 2\end{array}$ & $\begin{array}{c}2.22 \pm 0.20^{*} \\
71 \pm 2\end{array}$ \\
\hline FRC & $\begin{array}{l}\mathrm{L} \\
\% \text { control }\end{array}$ & $3.10 \pm 0.19$ & $\begin{array}{c}3.22 \pm 0.20 \\
104 \pm 1\end{array}$ & $\begin{array}{c}3.57 \pm 0.22 \\
115 \pm 2\end{array}$ & $\begin{array}{c}3.99 \pm 0.17 * \\
130 \pm 5\end{array}$ \\
\hline \multicolumn{2}{|c|}{ Borg scale score } & $0.2 \pm 0.1$ & $2.0 \pm 0.8$ & $2.9 \pm 1.0 *$ & $5.5 \pm 1.0 * *$ \\
\hline
\end{tabular}

Data are presented as mean \pm SEM. ${ }^{*}$ : measured at isovolume; ${ }^{+}$: last step ${ }^{*}$ : first step; ${ }^{*}: \mathrm{p}<0.01 ;{ }^{*}: \mathrm{p}<0.001$, versus control. IC: inspiratory capacity; FEV1: forced expiratory volume in one second; FEF25-75\%: forced mid-expiratory flow; FRC: functional residual capacity. 
Table 3. - Breathing pattern parameters during methacholine-induced bronchoconstriction

\begin{tabular}{ccccccccccc}
\hline & $\begin{array}{c}V \mathrm{~T} \\
\mathrm{~L}\end{array}$ & $\begin{array}{c}f \mathrm{R} \\
\mathrm{br} \cdot \mathrm{min}^{-1}\end{array}$ & $\begin{array}{c}V^{\prime} \mathrm{E} \cdot \mathrm{min}^{-1} \\
\mathrm{~s}\end{array}$ & $\begin{array}{c}t \mathrm{I} \\
\mathrm{s}\end{array}$ & $\begin{array}{c}t \mathrm{E} \\
\mathrm{s}\end{array}$ & $\begin{array}{c}t \text { tot } \\
\mathrm{s}\end{array}$ & $\begin{array}{c}V \mathrm{~T} / t \mathrm{I} \\
\mathrm{L} \cdot \mathrm{s}^{-1}\end{array}$ & $\begin{array}{c}V \mathrm{~T} / t \mathrm{E} \\
\mathrm{L} \cdot \mathrm{s}^{-1}\end{array}$ & $t \mathrm{I} / t$ tot & $t \mathrm{E} / t$ tot \\
\hline $\begin{array}{c}\text { Control } \\
\begin{array}{c}\mathrm{IC}>90 \% \\
\text { control* }\end{array}\end{array}$ & $0.76 \pm 0.05$ & $13.4 \pm 0.08$ & $10.0 \pm 0.7$ & $1.76 \pm 0.18$ & $2.87 \pm 0.19$ & $4.63 \pm 0.31$ & $0.464 \pm 0.050$ & $0.268 \pm 0.018$ & $0.38 \pm 0.02$ & $0.62 \pm 0.02$ \\
$\begin{array}{c}\mathrm{IC}<90 \% \\
\text { control }\end{array}$ & $0.74 \pm 0.07$ & $15.3 \pm 1.2$ & $10.3 \pm 0.8$ & $1.55 \pm 0.17$ & $2.59 \pm 0.22$ & $4.14 \pm 0.34$ & $0.470 \pm 0.037$ & $0.275 \pm 0.023$ & $0.37 \pm 0.02$ & $0.63 \pm 0.02$ \\
$\begin{array}{c}\text { Maximal } \\
\text { dose }\end{array}$ & $0.72 \pm 0.09$ & $18.4 \pm 2.9$ & $12.2 \pm 1.4$ & $1.54 \pm 0.22$ & $2.29 \pm 0.23$ & $3.79 \pm 0.43$ & $0.539 \pm 0.066$ & $0.332 \pm 0.038$ & $0.39 \pm 0.02$ & $0.61 \pm 0.02$ \\
\hline
\end{tabular}

Data are presented as mean \pm SEM. ${ }^{*}$ last step; ${ }^{+}$first step. $V$ T: tidal volume; $f \mathrm{R}:$ respiratory frequency; br: breaths: $V^{\prime} \mathrm{E}:$ minute ventilation; $t \mathrm{I}$ : inspiratory time; $t \mathrm{E}$ : expiratory time; $t$ tot: inspiratory + expiratory time; IC: inspiratory capacity.

obstruction the development of EFL during tidal breathing would promote the shortening of expiratory time due to premature, reflex activation of inspiratory muscles, thus increasing the EELV and actually preventing the occurrence of EFL [7]. According to the protocol of the above mentioned study, to detect EFL, partial forced flowvolume curves recorded at each stepwise-dose of MCh were superimposed at absolute lung volume on tidal flowvolume curves obtained before that stepwise-dose. When tidal expiratory flow at a given stepwise-dose eventually impinged on forced expiratory flow at the subsequent stepwise-dose, EFL conditions were said to have occurred [7].

This method of assessing EFL, however, is questionable even if partial forced flow-volume curves were obtained for some subjects by a body plethysmograph to avoid artefacts due to thoracic gas compression. In fact, to compare the expiratory flow during tidal breathing with that recorded during subsequent full or even partial forced expiration is intrinsically erroneous because the volumedependent changes in lung recoil and airway resistance and the time-dependent viscoelastic behaviour of the thoracic tissues differ because the two preceding inspiratory manoeuvres are dissimilar. Changes in time and volume history of the lung and airways during inspiration have been shown to influence the following expiratory flow rate at

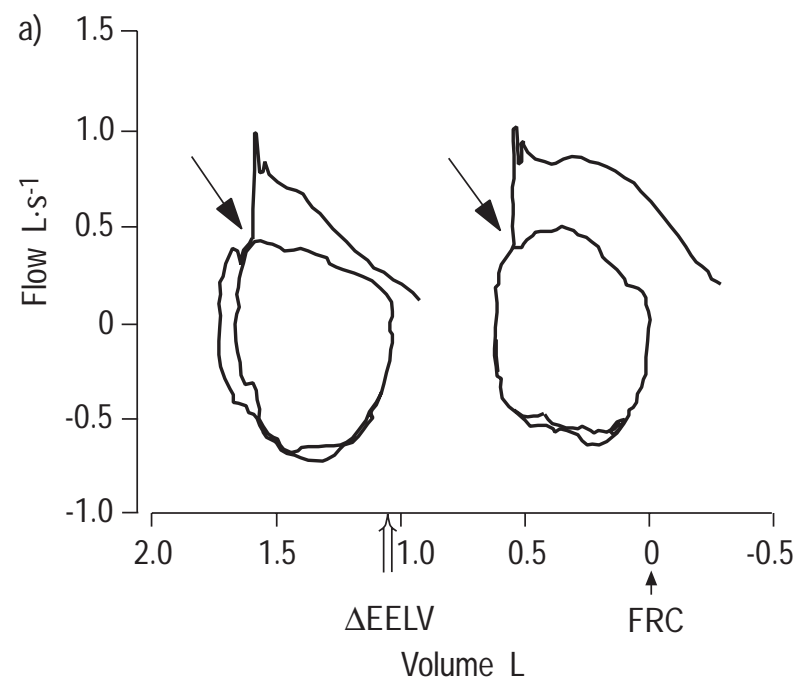

comparable lung volumes [17-19]. In contrast, the NEP method used in the current study appears to be more reliable in assessing EFL because the control and the NEP test breaths have similar lung volume and time history. Furthermore, this technique does not depend on patient cooperation and coordination $[8,15]$.

While in 3 subjects a sharp initial increase in EELV was induced by the MCh challenge, in the other subjects dynamic hyperinflation developed more gradually. Thus, at least in 7 subjects EELV could be clearly shown to have started to increase before EFL would have limited tidal expiratory flow if the subjects had continued to breathe at the control EELV (fig. 3).

These results support the concept that dynamic hyperinflation during acute bronchoconstriction in asthma does occur before the development of EFL, suggesting that the attainment of maximal expiratory flow during tidal breathing is not required in order for the "active" mechanisms to come into play. In fact, it is conceivable that the system may react before becoming overall flow-limited, even at end-expiration. The findings, however, do not exclude the possibility that scattered conditions of EFL in different lung regions with concomitant dynamic airway compression might play a role in promoting dynamic hyperinflation.

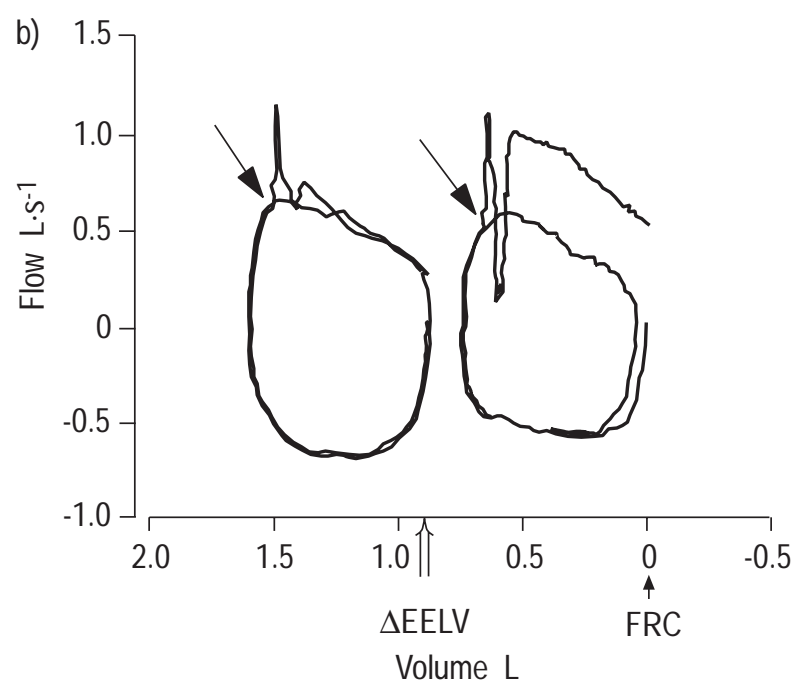

Fig. 2. - Tidal flow-volume loops under control conditions (second loop) and at maximum methacholine (MCh) dose (first loop) in two representative subjects (a) subject number 10, b) subject number 1 . In both subjects, expiratory flow limitation (EFL) was absent under control conditions. At maximal MCh dose, subject 1 exhibited EFL while subject 10 did not. With MCh in subjects 10 and 1 the end-expiratory lung volume (EELV) increased (1.05 and $0.9 \mathrm{~L}$, respectively) and forced expiratory volume in one second (FEV1) decreased (47 and 46\% from control, respectively). $\uparrow:$ negative expiratory pressure application; $\Uparrow$ : change in EELV $(\triangle E E L V)$; FRC: functional residual capacity. 


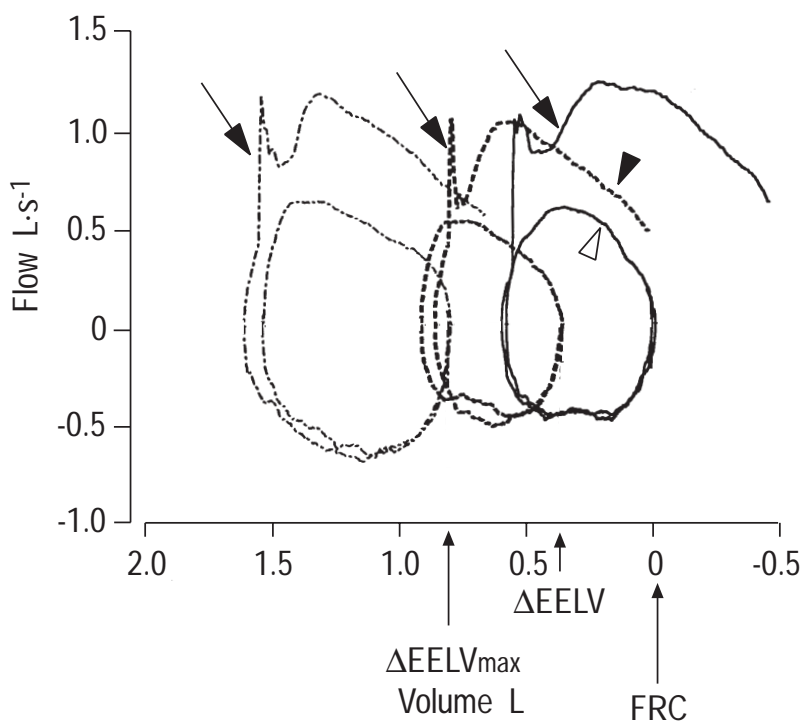

Fig. 3. - Three control tidal flow-volume loops with the corresponding negative expiratory pressure (NEP) test breath $(\downarrow)$ under control conditions, in the presence of a substantially increased end-expiratory lung volume (EELV) and at maximum response during methacholine (MCh)-induced bronchoconstriction in subject number 7. The flow during NEP when the elevation of the EELV was already present $(\boldsymbol{\nabla})$ was higher that the tidal expiratory flow in control conditions $(\nabla)$, indicating that dynamic hyperinflation occurred before expiratory flow limitation (EFL) had been attained. — : control; - - - : change from control in forced expiratory volume in one second $(\mathrm{FEV} 1)=22 \% ;-\cdot-$ : $\mathrm{FEV} 1=40 \%$; $\Delta$ : change; FRC: functional residual capacity.

Two out of 10 subjects exhibited EFL during MCh challenge, suggesting that, also in acute asthma, moderateto-severe bronchoconstriction may be associated with EFL. On the other hand, in line with a previous study [20], this finding indicates that EFL occurs rarely in asthmatics, especially compared to chronic obstructive pulmonary disease patients with similar decreases in FEV1.

Therefore, the possibility that EFL may occur should be taken into account and EFL correctly assessed in patients with severe asthma and dynamic pulmonary hyperinflation before applying continuous positive airway pressure (CPAP) (or positive end-expiratory pressure (PEEP)) to counterbalance the inspiratory threshold load due to the intrinsic PEEP (PEEPi), thus decreasing the inspiratory muscle's work and possibly reducing dyspnoea sensation.

While in the presence of EFL careful titration of CPAP (or PEEP) could effectively attain these goals with preservation of EELV [21], in the absence of EFL the application of CPAP (or PEEP) could be deleterious without expiratory muscle recruitment, resulting in further hyperinflation with severe consequences for inspiratory muscle performance and haemodynamics [22, 23].

In the subjects in the current study dyspnoea was not associated with the onset of EFL; conversely, in line with other more symptom-focused studies [13], the degree of dyspnoea was related to the dynamic hyperinflation $(\triangle \mathrm{EELV})$, being significantly present only after a $10 \%$ decrease in IC from baseline (table 2). Accordingly, in acute asthma, dyspnoea seems to be elicited by increased inspiratory work due to PEEPi rather than a flow-limiting dynamic airway compression. Moreover, as previously shown for progressive bronchoconstriction [24], as assessed in terms of $\triangle \mathrm{FEV} 1$, the increase in dyspnoea sen- sation with increasing dynamic hyperinflation, as assessed in terms of $\triangle \mathrm{IC}$, was markedly different from subject to subject. In other words, dyspnoea tends to worsen with the increase in EELV but in a highly variable manner among different subjects.

In summary, the results of this study indicate that in asthma, during methacholine-induced bronchoconstriction, dynamic hyperinflation in general develops without expiratory flow limitation, and expiratory flow limitation does not represent a triggering factor for generating dynamic hyperinflation because the increase in end-expiratory lung volume occurs in the absence of or well before expiratory flow limitation. The specific factors responsible for triggering the persistence of inspiratory muscle activity during expiration in the presence of acute bronchoconstriction in asthma have yet to be elucidated.

Acknowledgements. The authors are indebted to F. Dall'Ava Santucci for help in supporting this study. The technical assistance of P. Vallée has been invaluable.

\section{References}

1. Woolcock AJ, Rebuck AS, Cade JF, Read J. Lung volume changes in asthma measured concurrently by two methods. Am Rev Respir Dis 1971; 104: 703-709.

2. Martin JG. Respiratory mechanics in asthma. Eur Respir Rev 1993; 3: 14, 444-447.

3. Martin JG, Powell E, Shore S, Emrich J, Engel LA. The role of respiratory muscles in the hyperinflation of bronchial asthma. Am Rev Respir Dis 1980; 121: 443447.

4. Muller N, Bryan AC, Zamel N. Tonic inspiratory muscle activity as a cause of hyperinflation in histamine-induced asthma. J Appl Physiol 1980; 49: 869-874.

5. Collett PW, Brancatisano T, Engel LA. Changes in glottic aperture during bronchial asthma. Am Rev Respir Dis 1983; 128: 719-723.

6. Cormier Y, Lecours R, Legris C. Mechanisms of hyperinflation in asthma. Eur Respir J 1990; 3: 619-624.

7. Pellegrino R, Violante B, Nava S, Rampulla C, Brusasco V, Rodarte JR. Expiratory airflow limitation and hyperinflation during methacholine-induced bronchoconstriction. J Appl Physiol 1993; 75(4): 1720-1727.

8. Koulouris NG, Valta P, Lavoie A, et al. A simple method to detect expiratory flow limitation during spontaneous breathing. Eur Respir J 1995; 8: 306-313.

9. Sterk PJ, Fabbri LM, Quanjer $\mathrm{PhH}$, et al. Airway responsiveness: standardized challenge testing with pharmacological, physical and sensitizing stimuli in adults. Eur Respir J 1993; 6 (Suppl. 16): 53-83.

10. Borg GAV. Psychophysical basis of perceived exertion. Med Sci Sports Exerc 1982; 14: 377-381.

11. Melissinos CG, Mead J. Maximum expiratory flow changes induced by longitudinal tension on the trachea in normal subjects. $J$ Appl Physiol 1977; 43: 537-544.

12. Gardner RM, Hankinson JL, Clausen JL, Crapo RO, Johnson RO Jr, Epler GR. American Thoracic Society standardization of spirometry - 1987 update. Am Rev Respir Dis 1987; 13 6: 1285-1298.

13. Lougheed MD, Lam M, Forkert L, Webb KA, O'Donnell DE. Breathlessness during acute bronchoconstriction in asthma: pathophysiologic mechanism. Am Rev Respir Dis 1993; 148: 1452-1459. 
14. Quanjer PhH, Tammeling GJ, Cotes JE et al. Lung volumes and forced ventilatory flows: report of the Working Party 'standardization of lung function tests', European Community for Coal and Steel. Eur Respir J 1993; 6 (Suppl 16): 5-40.

15. Tantucci C, Mehiri S, Duguet A, et al. Application of negative expiratory pressure during expiration and activity of genioglossus in humans. J Appl Physiol 1998; 84(3): 1076-1082.

16. Wheatley JR, West S, Cala SJ, Engel LA. The effect of hyperinflation on respiratory muscle work in acute induced asthma. Am Rev Respir Dis 1990; 3: 625-632.

17. Fish JE, Ankin MG, Kelly JF, Peterman VL. Regulation of bronchomotor tone by lung inflation in asthmatic and nonasthmatic subjects. J Appl Physiol 1981; 50: 1079-1086.

18. Parham WM, Shepard RH, Norman PS, Fish JE. Analysis of time course and magnitude of lung inflation effects on airway tone: relation to airway reactivity. Am Rev Respir Dis 1983; 128: 240-245.

19. D'Angelo E, Prandi E, Marazzini L, Milic-Emili J. Dependence of maximal flow-volume curves on timecourse of preceding inspiration in patients with chronic obstructive lung disease. Am Rev Respir Dis 1994; 150 : 1581-1586.

20. Boczkowski J, Murciano D, Pichot M-H, Ferretti A, Pariente R, Milic-Emili J. Expiratory flow limitation in stable asthmatic patients during resting breathing. $\mathrm{Am} \mathrm{J}$ Respir Crit Care Med 1997; 156: 752-757.

21. Lougheed MD, Webb KA, O'Donnell DE. Breathlessness during induced lung hyperinflation in asthma: The role of the inspiratory threshold load. Am J Respir Crit Care Med 1995; 152: 911-920.

22. Tuxen DV. Detrimental effects of positive end-expiratory pressure during controlled mechanical ventilation in patients with severe airflow obstruction. Am Rev Respir Dis 1989; 140: 5-9.

23. Martin JG, Shore S, Engel LA. Effect of continuous positive airway pressure on respiratory mechanics and pattern of breathing in induced asthma. Am Rev Respir Dis 1982; 126: 812-817.

24. Bellofiore S, Ricciardolo FLM, Ciancio N, et al. Changes in respiratory drive account for the magnitude of dyspnoea during bronchoconstriction in asthmatics. Eur Respir J 1996; 9: 1155-1159. 